\title{
Facts and ideas from anywhere
}

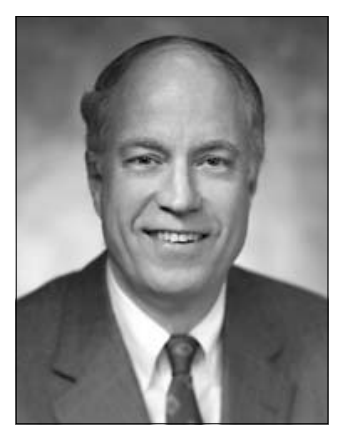

William C. Roberts, MD

\section{ANTIBIOTIC-RESISTANT ORGANISMS GROWN FROM RETAIL MEAT SAMPLES}

The October 18, 2001, issue of The New England Journal of Medicine contained 3 reports that indicate that meats purchased in US supermarkets frequently contain microorganisms resistant to antibiotics.

White and colleagues from College Park, Maryland, found that 20\% of samples of ground meat obtained in supermarkets were contaminated with salmonella and that $84 \%$ of the isolates were resistant to at least one antimicrobial (1). Meats are the chief source of human infection with antimicrobial-resistant salmonella. The transfer of resistant salmonella and Escherichia coli from food animals to humans is a common event. Earlier studies showed that Campylobacter jejuni, another important human pathogen, is frequently isolated from meat, particularly chicken, that is available in supermarkets, and the instance of fluoroquinolone-resistant strains has increased with the use of these drugs in animals.

McDonald and colleagues from 5 US medical centers found that at least $17 \%$ of chickens obtained in supermarkets in 4 states had strains of Enterococcus faecium that were resistant to quinupristin-dalfopristin, an antimicrobial recently approved for use in people (2). They ascribed the development of resistance in this important pathogen to the widespread use of virginiamycin in chicken feed.

Sorensen and colleagues from Copenhagen, Denmark, found that glycopeptide-resistant and streptogramin-resistant strains of Enterococcus faecium, isolated from chicken parts obtained at a grocery and from pigs after slaughter, were able to colonize up to 14 days in the intestinal tract of healthy volunteers (3). The emergence of glycopeptide-resistant strains is linked to the widespread use of avoparcin in animal feed in Europe. In 1997, its use was banned by countries in the European Union.

Over $80 \%$ of infections with salmonella and campylobacter in humans are acquired from food animals. One study in 1999 estimated that there were 1.4 million cases of illness due to salmonella and 2.4 million cases of illness due to campylobacter infection in the USA annually. In that study, 26\% of salmonella isolates and $54 \%$ of campylobacter isolates were resistant to at least one antimicrobial.

The use of antimicrobials in food animals selects for resistant strains and enhances their persistence in the environment. Drug resistance in salmonella and campylobacter can increase the frequency and severity of infections with such organisms, limit treat- ment options, and raise health care costs. The risk of infections with resistant strains of salmonella or campylobacter is increased when a person has taken an antimicrobial within a few weeks before the exposure.

Antimicrobials have been used in food animals in North America and Europe for 50 years. Among the most common are drugs that are either identical to or related to those administered to humans, including penicillins, tetracyclines, cephalosporins, fluoroquinolones, avoparcin, and virginiamycin. These antimicrobial agents are given to food animals as therapy for an infection or, in the absence of disease, for subtherapeutic purposes with the goals of growth promotion and improved nutritional benefits of the animal feed. The amounts of antimicrobials given to food animals relative to the amounts given to humans are uncertain since manufacturers are not required to provide precise production figures. It has been recently estimated that each year about 25 million pounds of antimicrobials are given to nonhuman animals for subtherapeutic purposes and about 2 million pounds for therapy; in contrast, only 3 million pounds are given to humans. An intense debate has raged over the past 30 years on the impact on human health of the use of antimicrobial agents in food animals.

Not all antimicrobial resistance in human pathogens, of course, can be ascribed to the use of these drugs in food animals. The use of antimicrobials in humans, much of which is inappropriate, is responsible for rising levels of resistance in organisms such as Streptococcus pneumoniae, Staphylococcus aureus, and Neisseria gonorrhoeae, as well as many bacteria acquired in hospitals. Human antimicrobial use may also lead to vancomycin-resistant enterococci, which currently accounts for $25 \%$ of nosocomial enterococcal infections in the USA. In some European countries, the rates of carriage of vancomycin-resistant enterococci in the general population range from $12 \%$ to $28 \%$, yet in most European hospitals the frequency of infection with these organisms is quite low. The opposite situation prevails in the USA. As reported by McDonald and colleagues and by other investigators, the rate of carriage of vancomycin-resistant enterococci in the general population is $1 \%$, whereas nosocomial infections with vancomycin-resistant enterococci are widespread in many hospitals in the USA. Although the transmission of vancomycinresistant enterococci in the USA has not been related to the use of antibiotics in food animals, the increasing burden of resistant Enterococcus faecium in our food chain and the ability of these strains to colonize the human intestine represent a potential threat.

These 3 studies and others indicate that antimicrobials should be used only when indicated in individual infected ani- 
mals for a targeted pathogen and prescribed by a veterinarian (4). The use of certain drugs that have important uses in humans, such as fluoroquinolones and third-generation cephalosporins, should be prohibited in nonhuman animals. The subtherapeutic use of these agents to promote growth and feeding efficiency should be banned, a move that would decrease the burden of antimicrobial resistance in the environment and provide healthrelated benefits to both human animals and nonhuman animals. The safest course, of course, is simply to not eat animal muscle, something our arteries would appreciate.

\section{CONTROLLING HIGH BLOOD PRESSURE}

The most important factors in acquiring and maintaining good health in the Western world are the following: 1) normal blood cholesterol level (total cholesterol $<150 \mathrm{mg} / \mathrm{dL}$ ); 2) normal blood pressure level $(\leq 120 / 80 \mathrm{~mm} \mathrm{Hg}) ; 3)$ normal blood glucose level ( $<110 \mathrm{mg} / \mathrm{dL}) ; 4$ ) normal body weight (body mass index $\left.\leq 25 \mathrm{~kg} / \mathrm{m}^{2}\right)$; 5) avoidance of cigarettes; and 6) safe driving and safe sex. The cholesterol level for the most part determines whether we develop symptomatic or fatal atherosclerotic disease; the blood pressure level for the most part determines whether or not we have stroke or aortic dissection; the body weight and blood glucose levels determine whether or not we get diabetes mellitus and some other devastating consequences from weighing too much; and refraining from smoking prevents some cancers, including one of the most common ones (lung cancer).

Of Americans over age 20, $>50 \%$ have elevated blood cholesterol levels, about $25 \%$ have elevated blood pressure levels, about $60 \%$ are overweight and half of them are obese, and approximately $25 \%$ smoke cigarettes. One doesn't have to go to a physician to know whether he or she smokes or whether he or she weighs too much. Determining blood cholesterol and blood pressure levels, however, usually requires a visit to a physician. But just because one goes to a physician does not mean that an elevated cholesterol or an elevated blood pressure will be treated, and even if a medicine is given for either or both of those elevations, it does not mean that the blood cholesterol level or the blood pressure level will be brought down to normal. And yet, the health of most of us will be determined by whether or not we can and do control these 6 factors.

Hyman and Pavlik analyzed 16,095 adults who were at least 25 years old and for whom blood pressure values and hypertensive medication status were known (5). From analysis of these individuals, these 2 authors projected their findings on the entire US population aged 25 or over. They estimated that 42 million people in the USA have hypertension (systolic blood pressure $\geq 140 \mathrm{~mm} \mathrm{Hg}$ and/or diastolic blood pressure $\geq 90 \mathrm{~mm}$ $\mathrm{Hg}$ ): $31 \%$ (13 million) of them are unaware of their hypertension; $17 \%$ (7 million) are aware of their condition but are not being treated; $29 \%$ (12 million) are being treated but their hypertension remains uncontrolled; and only $23 \%$ (10 million) are taking medications that control their hypertension. Although persons $\geq 65$ years of age represent only $19 \%$ of our population, they constitute $45 \%$ of the persons who are unaware of their condition; $32 \%$ of them are aware of their condition but are not being treated, and $57 \%$ of them have treated but uncontrolled hypertension. The largest segment of our population consists of those 25 to 44 years of age, and $22 \%$ of them are unaware of their hypertension, $27 \%$ are aware but not being treated, and $<10 \%$ are being treated but the hypertension is uncontrolled. Among those being treated, hypertension is controlled in $65 \%$ of those 25 to 44 years old, $52 \%$ of those 45 to 64 years old, and only $34 \%$ of those $\geq 65$.

Before this study most physicians apparently believed that limited control of hypertension was attributable to lack of access to health care, noncompliance with treatment, and racial and ethnic factors. The present study shows that most cases of uncontrolled hypertension in the USA consist of isolated, mild systolic hypertension in older adults, most of whom have access to health care and relatively frequent contact with physicians. Physicians are often reluctant to treat systolic hypertension aggressively, but the finding of elevated systolic blood pressure and pulse pressure is not only predictive of an increased risk of cardiovascular events but also indicative of existing vascular abnormalities. We can and must do better.

\section{IMPACT OF HIGH "NORMAL" BLOOD PRESSURE ON RISK OF CARDIOVASCULAR DISEASE}

At birth our blood pressure is approximately $90 / 60 \mathrm{~mm} \mathrm{Hg}$, and in societies who eat no measurable salt it remains 90/60 during the entire lifetime. For decades in the USA and in most Western societies, the upper limit of normal blood pressure in adults has been considered to be $140 / 90 \mathrm{~mm} \mathrm{Hg}$. Using the 6859 participants in the Framingham Heart Study, Vasan and colleagues from Massachusetts classified subjects into 1 of 3 nonhypertensive blood pressure categories based on baseline findings: optimal (systolic pressure $<120$ and diastolic pressure $<80 \mathrm{~mm}$ $\mathrm{Hg}$ ), normal (systolic pressure 120 to 129 or diastolic pressure 80 to $84 \mathrm{~mm} \mathrm{Hg}$ ), or high-normal (systolic pressure 130 to 139 or diastolic pressure 85 to $89 \mathrm{~mm} \mathrm{Hg}$ ) (6). If the systolic and diastolic pressure readings belonged to different categories, the higher of the 2 readings was used to assign the blood pressure category. No subject had cardiovascular disease clinically at the baseline examination. At baseline, the blood pressure was highnormal in $25 \%$ of subjects, normal in $33 \%$, and optimal in the remainder.

During a mean follow-up of 11 years, 397 study subjects had a first cardiovascular event, including 72 deaths from cardiovascular disease, 190 recognized acute myocardial infarcts, 85 strokes, and 50 cases of congestive heart failure. Cardiovascular event rates increased in a stepwise manner across the 3 blood pressure categories. The 10-year cumulative incidence of cardiovascular disease in subjects 35 to 64 years of age who had highnormal blood pressure was $4 \%$ for women and $8 \%$ for men; in subjects 65 to 90 years old, the incidence was $18 \%$ for women and 25\% for men. Compared with optimal blood pressure, highnormal blood pressure was associated with a risk factor-adjusted hazard ratio for cardiovascular disease of 2.5 in women and 1.6 in men. Thus, high-normal blood pressure is associated with an increased risk of cardiovascular disease. It is not known whether lowering high-normal pressures reduces the risk of cardiovascular disease, but it is likely that it would.

\section{HORMONE REPLACEMENT THERAPY AND BLOOD PRESSURE}

The frequency of high blood pressure in postmenopausal women exceeds that in age-matched men. Scuteri and colleagues 
from Baltimore, Maryland, studied 226 healthy, normotensive postmenopausal women (mean age $64 \pm 10$ years) and followed them for $6 \pm 5$ years (7). Systolic blood pressure at baseline was similar in the 75 women who used both estrogen and progestin and in the 149 who used neither $(134 \pm 16 \mathrm{~mm} \mathrm{Hg})$. Over time, average systolic blood pressure increased less in hormone replacement therapy (HRT) users than in nonusers, and the increase was independent of other cardiovascular risk factors, physical activity, and alcohol use. HRT users who were 55 years of age at their first visit had an 8- $\mathrm{mm} \mathrm{Hg}$ average increase in systolic blood pressure over 10 years; in contrast, the average increase in nonusers over that time was $19 \mathrm{~mm} \mathrm{Hg}$. Diastolic blood pressure did not change over time in either group. Thus, postmenopausal women taking HRT have a smaller increase in systolic blood pressure over time than those not taking this therapy.

\section{HORMONE REPLACEMENT THERAPY AND DRY EYE SYNDROME}

Dry eye syndrome or keratoconjunctivitis sicca damages the ocular surface and can cause debilitating symptoms of dryness and irritation. Dry eye syndrome is associated with an enhanced risk of corneal infection and, when severe, can cause permanent visual impairment. Treatments for dry eye syndrome are generally costly and inadequate. It is one of the leading causes of patient visits to both ophthalmologists and optometrists. HRT is used by an estimated $38 \%$ of postmenopausal women in the USA. Although HRT has a clear role in the treatment of a variety of menopausal symptoms and may confer other health benefits, HRT may have adverse effects on the ocular surface.

Because of little data on the relation of HRT and dry eye syndrome, Schaumberg and associates from Boston, Massachusetts, studied 36,995 women in the Women's Health Study (8). Among the women with data on dry eye syndrome, 25,665 were postmenopausal. After excluding some for various reasons, 25,389 remained: $61 \%$ had used HRT at some time and $90 \%$ were current users. Use of HRT was significantly related to the prevalence of dry eye syndrome. Women who never used HRT had the lowest prevalence $(6 \%)$, whereas women who used estrogen alone had the highest prevalence $(9 \%)$ and women who used a combination of estrogen plus progesterone/progestin had a prevalence that was intermediate between that of nonusers and users of estrogen alone (7\%). These data suggest that women who use HRT, particularly estrogen alone, are at increased risk of dry eye syndrome.

\section{HIGH BLOOD CHOLESTEROL AWARENESS}

The Centers for Disease Control and Prevention (CDC) analyzed data from the Behavioral Risk Factor Surveillance System for 1991 through 1999 for 412,332 persons aged $\geq 20$ years from 50 states and the District of Columbia (9). Survey participants were asked whether they had ever had their blood cholesterol level checked and, if so, whether a physician or health care provider had ever told them that their blood cholesterol level was high. Those who reported having ever had their blood cholesterol checked were included in the analysis, and those who reported that they had been told they had high blood cholesterol were classified as being aware that they had high blood cholesterol $(n=120,450)$. The prevalence of high blood cholesterol awareness among the persons screened increased from $26 \%$ in 1991 to $29 \%$ in 1999 . The percentage of persons who had ever had their cholesterol tested and who reported having been told that they had high blood cholesterol was consistently higher for successive age groups (from 19\% among those aged 20 to 44 years to $43 \%$ among those aged $\geq 65$ years for 1999 ).

The fate of most Americans is determined by blood cholesterol, blood pressure, blood glucose, body weight, and number of cigarettes smoked. It's difficult to do anything about the cholesterol level if neither the patient nor the physician knows what it is. We certainly have a long way to go to improve the health of Americans. An increase in awareness of 3\% during the 1990s is hardly something to be proud of.

\section{EGG-LAYING HENS IN THE USA}

I learned recently when watching a news TV show that we have 250 million egg-laying hens in the USA — almost as many as people in the USA - and they lay 80 billion eggs a year. Egg yolks are the most concentrated collection of cholesterol that we can eat. I wonder how many atherosclerotic plaques 80 billion eggs produce.

\section{EFFECT OF STATINS ON AORTIC VALVE STENOSIS}

It was speculated several years ago that statins might retard or slow development of calcific deposits in congenitally bicuspid aortic valves and possibly also in stenotic 3-cuspid aortic valves among older adults (10). Proof of this thesis was recently provided by Novaro and colleagues from Cleveland who studied 174 patients (mean age $68 \pm 12$ years) with mild to moderate aortic stenosis and normal left ventricular function (11). Echocardiograms were performed from 12 to 40 months (mean 21 months) apart. On average, patients taking a statin were older and had a higher prevalence of systemic hypertension, diabetes mellitus, and coronary artery disease. Baseline levels of total and low-density lipoprotein (LDL) cholesterol, percentage of patients with congenitally bicuspid aortic valves, peak systolic pressure gradients (average $29 \mathrm{~mm} \mathrm{Hg}$ [range 21-38]), and left ventricular ejection fractions (averaging 57\%) were similar between the 2 groups. The 57 patients treated with a statin had a smaller increase in peak systolic gradients than did the 117 patients not so treated. The average decrease in aortic valve area over the follow-up period for the nonstatin group was $0.19 \pm 0.25 \mathrm{~cm}^{2}$ and for the statin group, $0.12 \pm 0.22 \mathrm{~cm}^{2}$. The annualized decrease in aortic valve area for the nonstatin group was $0.11 \pm 0.18 \mathrm{~cm}^{2}$ and for the statin group, $0.06 \pm 0.16 \mathrm{~cm}^{2}$, a $45 \%$ less progression in valve area per year. Thus, the statin-treated patients, despite having a higher risk profile for progression, had reduced aortic stenosis progression compared with those not treated with a statin. The statin-treated patients over the study period had a significant reduction in LDL cholesterol and a significant increase in high-density lipoprotein cholesterol, changes not seen in the nonstatin group. The change in peak systolic gradient correlated with the decrease in LDL cholesterol.

\section{EFFECTS OF ANGIOTENSIN-CONVERTING ENZYME INHIBITORS AND BETA-BLOCKERS IN BLACKS VS WHITES WITH CONGESTIVE HEART FAILURE}

Angiotensin-converting enzyme (ACE) inhibitors and betablockers have been shown to improve outcomes in patients with congestive heart failure. Two studies published in 1999, however, 
showed that both enalapril and bucindolol significantly reduced the risk of death among white patients with heart failure but not among black patients. Exner and colleagues analyzed data from 2 large randomized trials comparing enalapril with placebo in patients with left ventricular dysfunction (12). Although the white and black patients had similar demographic and clinical characteristics, the black patients had higher rates of death from any cause (12 per 100 person-years vs 10 per 100 person-years) and of hospitalization for heart failure (13 per 100 person-years vs 8 per 100 person-years). Despite similar doses of the drug in the 2 groups, enalapril compared with placebo was associated with a $44 \%$ reduction in the risk for hospitalization in white patients but no reduction among black patients. At 1 year, enalapril therapy was associated with significant reductions from baseline in systolic (mean $5 \mathrm{~mm} \mathrm{Hg}$ ) and diastolic (mean $4 \mathrm{~mm}$ $\mathrm{Hg}$ ) blood pressure among white patients but not among black patients. No significant change in the risk of death was observed in association with enalapril therapy in either group.

Yancy and colleagues studied 217 black and 877 nonblack patients with a left ventricular ejection fraction $\leq 35 \%$ and treated half of them with carvedilol ( 6.25 to $50 \mathrm{mg}$ twice daily) for up to 15 months (13). Compared with placebo, carvedilol lowered the risk of death from any cause or hospitalization for any reason by $48 \%$ in the black patients and by $30 \%$ in the nonblack patients (insignificant difference). Carvedilol reduced the risk of worsening heart failure by $54 \%$ in the black patients and by $51 \%$ in the nonblack patients (insignificant difference).

\section{LEFT VENTRICULAR ASSIST DEVICE FOR END-STAGE HEART FAILURE}

Heart failure affects nearly 5 million Americans, with 550,000 new cases diagnosed annually. The annual cost estimates are from $\$ 10$ billion to $\$ 40$ billion. The 5 -year survival rate of all patients with heart failure is approximately $50 \%$, and the 1year mortality rate of those with advanced failure is $>50 \%$. Rose and colleagues for the REMATCH Study Group randomly studied 129 patients with end-stage heart failure who were ineligible (because of age, insulin-dependent diabetes, or chronic renal failure) for cardiac transplantation and assigned 68 of them to receive a left ventricular assist device and 61 to receive no assist device but optimal medical therapy (14). Those with the assist device had a $48 \%$ reduction in the risk of death from any cause compared with the medical therapy-only group. The rates of survival at 1 year were $52 \%$ in the device group and $25 \%$ in the medical therapy-only group, and the rates at 2 years were $23 \%$ and $8 \%$, respectively.

The frequency of serious adverse events in the device group, however, was 2.4 times that of the medical therapy group. Within 3 months after implantation, the probability of infection of the left ventricular assist device was $28 \%$, and although most of the infections were in the driveline tract and pocket, fatal sepsis was common. Within 6 months after implantation, the frequency of bleeding was $42 \%$. No device system had failed by 12 months. The quality of life was significantly improved at 1 year in the device group.

Thus, the use of a left ventricular assist device in patients with end-stage heart failure resulted in a clinically meaningful survival benefit and an improved quality of life. Although the cause of the heart failure in these patients was not described, I suspect that in most the cause was atherosclerotic coronary artery disease, which is preventable in most of us.

\section{USING AN ANGIOTENSIN-CONVERTING ENZYME INHIBITOR TO PREVENT DEVELOPMENT OF DIABETES MELLITUS}

Diabetes mellitus is a growing problem worldwide, particularly in North America. Many of its complications can be reduced or prevented by improving glucose control, lowering blood pressure and blood lipid levels, discontinuing smoking, and taking ACE inhibitors. Preventing diabetes mellitus from occurring in the first place obviously is the best way to prevent its multiple arterial, renal, and ocular complications. Exercise and maintenance of an ideal body weight are effective in preventing diabetes, but of course maintaining ideal body weight or losing weight is uncommon, and many exercise goals vanish rapidly.

The HOPE study demonstrated that ramipril, an ACE inhibitor, reduces the frequency of acute myocardial infarction, stroke, death, the development of diabetic nephropathy, and the development of diabetes in the first place. In a more recent article, Yusuf and colleagues described in detail why the development of diabetes decreased by nearly $35 \%$ in their ramipril group compared with their placebo group (15). The study included 5720 patients. The authors found that ACE inhibitors reduced insulin resistance in skeletal muscles and increased insulin-mediated glucose disposal, thereby decreasing the need for pancreatic insulin secretion. The increased insulin-mediated glucose uptake by skeletal muscle in response to an ACE inhibitor appears to be due to increased bradykinin-mediated nitric oxide production and not to reductions in angiotensin-2 production or action.

\section{ANGIOTENSIN RECEPTOR ANTAGONIST AND NEPHROPATHY FROM DIABETES MELLITUS}

Lewis and colleagues studied 1715 hypertensive patients with nephropathy secondary to type 2 diabetes mellitus (16). They found that during a mean follow-up of 2.6 years, irbesartan $(300$ $\mathrm{mg}$ daily) decreased the risk of doubling of the serum creatinine concentration by $33 \%$ compared with the placebo group and by $37 \%$ compared with the amlodipine (10 mg daily) group. Further, irbesartan decreased the relative risk of end-stage renal disease by $23 \%$.

Brenner and colleagues found that losartan (50 to $100 \mathrm{mg}$ once daily) reduced the incidence of a doubling of the serum creatinine concentration by $25 \%$ and end-stage renal disease by $28 \%$ compared with the placebo group among 1513 patients (17). Thus, both irbesartan and losartan confer significant renal benefits in patients with type 2 diabetes mellitus and nephropathy.

\section{FATTEST CITIES IN THE USA}

Texas contains 4 of the 25 fattest cities in the USA: first on the list is Houston, 11th is Fort Worth, 15th is El Paso, and 16th is Dallas (18). Of the 25 fittest cities in the USA, only 2 are in Texas: Austin is 17th and San Antonio, 25th.

\section{USEFULNESS OF INSULIN THERAPY IN CRITICALLY ILL PATIENTS IN THE SURGICAL INTENSIVE CARE UNIT}

Hyperglycemia and insulin resistance are common in critically ill patients, even if they have not previously had diabetes 
mellitus. Whether normalization of the blood glucose levels with insulin therapy improves the prognosis for such patients is not known. Van den Berghe and colleagues from Leuven, Belgium, studied 1548 patients, 765 of whom received insulin therapy to maintain blood glucose between 80 and $110 \mathrm{mg} / \mathrm{dL}$ and 783 of whom (conventional treatment) received insulin only if the blood glucose was $>215 \mathrm{mg} / \mathrm{dL}$ with maintenance of glucose between 180 and $200 \mathrm{mg} / \mathrm{dL}$ (19). A total of 477 of the $765 \mathrm{pa}$ tients receiving intensive insulin treatment $(62 \%)$ and 493 of the 783 patients receiving conventional treatment (63\%) had had cardiac surgery. At 12 months, intensive insulin therapy had reduced mortality from $8 \%$ with conventional treatment to $4.6 \%$.

The benefit of intensive insulin therapy was attributed to its effect on mortality among patients who were in the intensive care unit for $>5$ days $(20.2 \%$ with conventional treatment and $10.6 \%$ with intensive insulin therapy). The greatest reduction in mortality involved patients with multiple-organ failure with sepsis. Intensive insulin therapy also reduced overall in-hospital mortality by $34 \%$, bloodstream infections by $46 \%$, acute renal failure requiring dialysis or hemofiltration by $41 \%$, the median number of red blood cell transfusions by $50 \%$, polyneuropathy by $44 \%$, and the need for prolonged mechanical ventilation and intensive care. Thus, intensive insulin therapy to maintain blood glucose $\leq 110 \mathrm{mg} / \mathrm{dL}$ reduces morbidity and mortality among critically ill patients in the surgical intensive care unit.

\section{CARDIAC REHABILITATION}

Elsewhere in this issue is an interview with Julie O'Bryan, who describes in detail the cardiac rehabilitation program at Baylor University Medical Center. Additional information on this topic can be obtained from a beautiful review by Philip Ades in the September 20, 2001, issue of The New England Journal of Medicine (20).

\section{PROPRANOLOL AFTER SEVERE BURNS}

Severe burns produce a hypermetabolic state with increased energy expenditure and protein breakdown leading to loss of lean body mass and muscle wasting. The muscle breakdown continues for at least several months after severe burns. Catecholamines, the primary mediators of the hypermetabolic response, increase as much as 10-fold after severe burns or trauma. Herndon and colleagues from Galveston, Texas, postulated that long-term betablockade with propranolol would decrease the rate of muscleprotein catabolism (21). They studied 25 children with burns covering $>40 \%$ of body surface area: 13 received oral propranolol for at least 2 weeks and 12 served as untreated controls. Propranolol significantly decreased resting energy expenditure and the net protein balance increased by $82 \%$ over the baseline values, whereas in the control group it increased by $27 \%$. The fat-free mass did not change substantially in the propranolol group and decreased $9 \%$ in the control group. Thus, in children with burns, treatment with propranolol during hospitalization attenuates hypermetabolism and reverses muscle-protein catabolism.

\section{RISK OF UTERINE RUPTURE DURING LABOR AMONG WOMEN WITH A PRIOR CESAREAN DELIVERY}

Each year in the USA, approximately $60 \%$ of pregnant women with a prior cesarean delivery attempt labor. Concern persists that a trial of labor may increase the risk of uterine rupture, an uncommon but serious obstetrical complication. LydonRochelle and colleagues from Seattle, Washington, conducted a population-based retrospective analysis using data from all primiparous women who gave birth to live singleton infants by cesarean section in civilian hospitals in Washington State from 1987 through 1996 and who delivered a second singleton child during the same period (a total of 20,095 women) (22). Uterine rupture occurred at a rate of 1.6 per 1000 women with repeated cesarean delivery without labor ( 11 women), 5.2 per 1000 with spontaneous onset of labor (56 women), 7.7 per 1000 among women whose labor was induced without prostaglandins (15 women), and 24.5 per 1000 women with prostaglandin-induced labor ( 9 women). The relative risk of uterine rupture among women with spontaneous onset of labor was 3.3, with induction of labor without prostaglandins 4.9 , and with induction with prostaglandins 15.6. Thus, for women with a prior cesarean delivery, the risk of uterine rupture is higher among those whose labor is induced than among those with repeated cesarean delivery without labor. Labor induced with a prostaglandin confers the highest risk.

This article was followed by an editorial by Michael F. Greene from the Massachusetts General Hospital (23). He asked, "Given the potential risks, why might a woman choose a trial of labor?" Women who successfully deliver vaginally generally have less postpartum discomfort, shorter hospital stays, and shorter periods of disability than women who undergo repeated cesarean section. A trial of labor may be associated with a lower risk of fever than elective repeated cesarean section. Women who plan future pregnancies may prefer to avoid repeated cesarean deliveries that further increase the risks of uterine rupture, placenta accreta, and morbidity related to multiple abdominal operations. Finally, there may be social and cultural reasons why some women prefer vaginal delivery.

The process of obtaining informed consent for medical care requires that physicians provide patients with the information that a reasonable person would want under the circumstances. Most reasonable women considering a trial of labor after a prior cesarean delivery would want to know that spontaneous labor is associated with a tripling of the risk of uterine rupture and that induction of labor with prostaglandins is associated with an increase in that risk by a factor of 15 . Should rupture occur, the risk of perinatal mortality increases by a factor of 10 . Some reasonable persons may conclude that these absolute risks are so small that they are worth taking and are outweighed by the benefits of a successful vaginal birth. After a thorough discussion of the risks and benefits of attempting a vaginal delivery after a cesarean section, Michael Greene's unequivocal recommendation is elective repeat cesarean section. Thus, he agrees with the mantra "Once a cesarean, always a cesarean."

\section{AUTO-CESAREAN SECTION}

A 42-year-old woman, the wife of a Turkish peasant and near the end of pregnancy, had been bedridden for 8 months because of great weakness and pain in the lower extremities, and she feared she would die before the child could be born (24). She took an ordinary pocketknife, cut open her abdomen, and extruded the child. She then lost consciousness. When conscious- 
ness returned, the woman awakened her 13-year-old daughter, sleeping in the same room, and asked her to sew up the abdomen. This was done with the aid of a domestic needle and waxed hemp thread. A physician, called 2 days later, found the patient to be emaciated and anemic, with signs of old pulmonary tuberculosis. He estimated that she had lost 2 quarts of blood during the delivery. The incision, approximately $16 \mathrm{~cm}$ long and extending from above the pubic bone to just above the umbilicus, was healing by primary union despite its being dressed with moss and a soiled rag. The uterus was enlarged but not unduly tender. An odorless bloody-serous flow oozed from the uterus. The wall of the uterus had not been closed. The infant was $49 \mathrm{~cm}$ long and weighed $3000 \mathrm{~g}$.

The case is remarkable for the operation itself, the absence of serious hemorrhage, the spontaneous closure of the uterus, the absence of infection, and the recovery of both mother and child.

\section{MATERNAL INJURY AND FETAL DEATH}

Trauma during pregnancy has been recognized as an important cause of adverse fetal and maternal outcomes. Most early reports focused primarily on its incidence from falls, blows, and assaults. Since about 1965, automobile crashes have received the most attention. A recent study by Weiss and colleagues from Pittsburgh, Pennsylvania, described 240 traumatic fetal injury deaths occurring in a 3 -year period in 16 states (25). Motor vehicle crashes were the leading traumatic mechanism $(82 \%$ of cases for an incidence of 2.3 fetal deaths per 100,000 live births), followed by firearm injuries ( $6 \%$ of cases), and falls ( $3 \%$ of cases).

\section{OTITIS MEDIA IN CHILDREN}

Giebink from Minneapolis, Minnesota, reviewed pneumococcal infections in children (26). Otitis media in children leads to $>20$ million visits to physicians annually in the USA. By 3 years of age, $80 \%$ of all children in the USA have had at least 1 episode of otitis media, and 50\% have had at least 3 episodes. Recurrent otitis media has its onset almost exclusively before a child's second birthday. Streptococcus pneumoniae (pneumococcus) is the most common cause of otitis media, accounting for about $50 \%$ of all cases. Antibiotics are prescribed empirically to virtually all children in the USA who have acute otitis media. Yet, $70 \%$ of severe cases and $90 \%$ of mild cases of acute otitis media resolve spontaneously. Moreover, approximately $20 \%$ of samples of middle ear fluid from patients with acute otitis media do not contain viable bacteria. Unfortunately, it is difficult and time consuming to sample middle-ear fluid for culture.

Several risk factors predispose to otitis media and drugresistant $S$. pneumoniae disease: male sex, attendance at a child care center outside the home, the absence of breastfeeding, passive exposure to tobacco smoke, previous antibiotic treatment when $<2$ years of age, and having a sibling with a history of recurrent otitis media.

In addition to causing otitis media, $S$. pneumoniae also causes more serious childhood illnesses. At least 1 million children die of pneumococcal infections (pneumonia, meningitis, and bacteremia) each year, mostly in developing countries. Pneumococcal meningitis has a higher mortality rate and more neurologic sequelae than meningitis due to Haemophilus influenzae or Neisseria meningitidis infection. About $30 \%$ of cases of community- acquired pneumonia in children are caused by pneumococcus. The overuse of antibiotics has contributed to the rapidly increasing prevalence of drug-resistant $S$. pneumoniae.

In February 2000, the Food and Drug Administration (FDA) licensed a 7-valent pneumococcal conjugate vaccine (pneumococcal-CRM197, Wyeth Lederle), which is recommended for routine use in infants. This vaccine, together with the identification of risk factors for otitis media and pneumococcal colonization of the nasopharynx, provides new opportunities for preventing and managing pneumococcal disease. Given the increasing prevalence of pneumococci with resistance to multiple antimicrobial drugs, these new approaches should find immediate use.

\section{SOUTH AFRICA AND AIDS}

AIDS accounted for about a quarter of all deaths in South Africa in the year 2000 and has become the country's largest single cause of death, according to a report released by the South African Medical Research Council (27). The report projects that the number of AIDS deaths will rise within this decade "to more than double the number of deaths due to all other causes, resulting in 5 to 7 million AIDS deaths in South Africa by 2010." Similar mortality rates were seen in neighboring Zimbabwe 8 years earlier.

\section{SUICIDE PREVENTION}

Surgeon General David Satcher recently released the nation's first coordinated suicide prevention strategy, a broad public health-oriented plan that calls for increased awareness, reduced stigma associated with mental health care, and a host of new community-based programs (28). Each year in the USA, 30,000 people take their own lives and another 650,000 attempt to do so, so the problem is a major one (Figure 1).

Emergency room physicians can help decrease suicide deaths according to the surgeon general's plan. For every person who dies of suicide, 22 others visit emergency departments for suicidal behavior, and these patients often do not receive appropriate follow-up care. At some emergency departments, every patient suspected of attempting suicide or complaining of suicide ideation receives a psychiatric consultation, but patients may wait

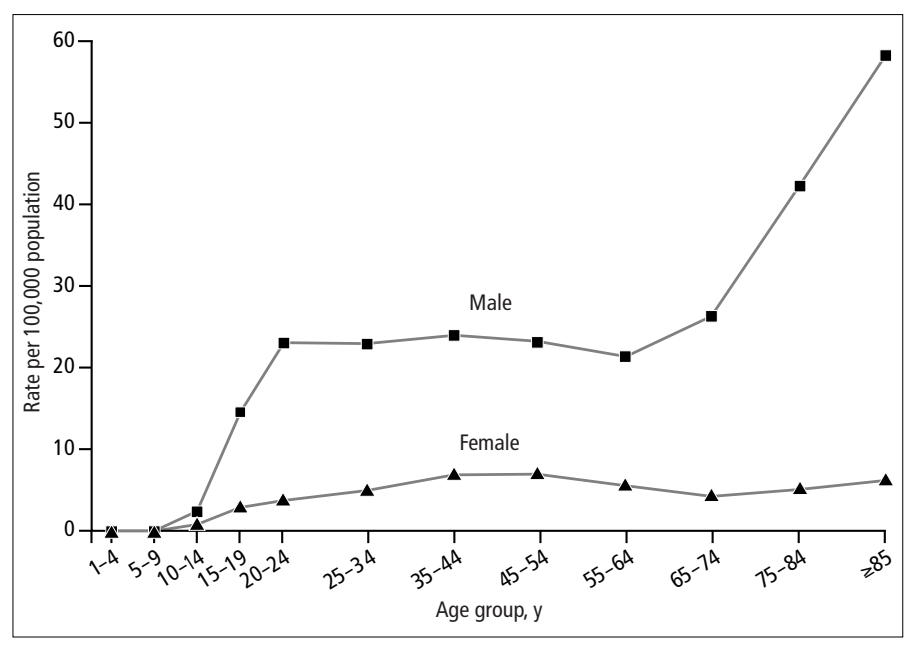

Figure 1. US suicide rates by age group and sex, 1998. Source: Centers for Disease Control and Prevention. 
10 hours or so to see the on-call psychiatrist. Studies during the 1990s have shown that many persons who commit suicide, perhaps as many as two thirds, visit a physician in the month prior to their death, meaning that health care professionals often are provided opportunities to save lives. Identifying potential suicide victims, however, is not always easy. The surgeon general has called for development of more effective screening tools. Since guns are used by $60 \%$ of suicide victims, a better control of that weapon surely would be helpful.

\section{NONSTEROIDAL ANTI-INFLAMMATORY DRUGS AND ALZHEIMER'S DISEASE}

The dementia of Alzheimer's disease has an insidious onset and a gradually progressive course. Although its pathogenesis is controversial, the process is widely believed to begin in midlife or earlier, decades before the appearance of symptoms. At that point a cascade of events occurs, including accumulation of extracellular beta-amyloid plaques and intraneuronal neurofibrillary tangles. These changes lead to a gradual loss of synapses and, subsequently, of nerve cell bodies in the hippocampus and cortex. Eventually, the losses overwhelm the capacities of compensatory and redundant pathways in the brain circuitry (cerebral reserve), and symptoms appear.

Inflammatory mechanisms have been proposed as important mediators in the pathogenetic cascade of Alzheimer's disease. Several studies in the early 1990s suggested that anti-inflammatory treatments, particularly nonsteroidal anti-inflammatory drugs (NSAIDs), were associated with delayed or reduced occurrence of Alzheimer's disease. More recent studies have been negative. In 'T Veld and colleagues from Rotterdam, The Hague, and Bethesda studied the usefulness of NSAIDs in preventing Alzheimer's disease and vascular dementia prospectively in 6989 subjects $\geq 55$ years of age who were free of dementia at baseline (29). The authors defined 4 categories of use: nonuse; short-term use ( $\leq 1$ month); intermediate-term use ( $>1$ and $<24$ months), and long-term use ( $\geq 24$ months). During an average follow-up of nearly 7 years, dementia developed in 394 subjects, of whom 293 had Alzheimer's disease, 56 had vascular dementia, and 45 had other types of dementia. The relative risk of Alzheimer's disease in subjects with short-term use of NSAIDs was 0.95 ; in those with intermediate-term use, 0.83 ; and in those with longterm use, 0.20 . The use of NSAIDs was not associated with a reduction in the risk of vascular dementia. Thus, the long-term use of NSAIDs may protect against development of Alzheimer's disease but not against vascular dementia.

\section{RELATION OF ALCOHOL TO BREAST CANCER}

The association of alcohol consumption with increased risk of breast cancer has been a consistent finding in most epidemiologic studies during the past 20 years. Singletary and Gapstur from Illinois summarized information on this association (30). Women consuming alcohol have increased estrogen and androgen levels, and that may be an important mechanism of how alcohol increases breast cancer frequency. Susceptibility to the breast cancer-enhancing effect of alcohol also may be affected by dietary factors (such as low folate intake), lifestyle habits (HRT, for example), or biologic characteristics (such as tumor hormone receptor status). Alcohol abuse and excessive drink- ing ( $\geq 3$ drinks per day) should be discouraged in light of the numerous deleterious health consequences accompanying such behavior. For the sporadic or occasional social drinker ( $\leq 1$ drink per day), there is little evidence that alcohol consumption increases breast cancer risk. Regular consumption of 1 to 2 drinks per day may contribute to a modest increase in risk. Alcohol intake is one of the few modifiable breast cancer risk factors yet identified.

\section{OUTCOMES OF WEEKDAY VS WEEKEND HOSPITAL ADMISSIONS}

Bell and Redelmeier from Toronto, Canada, analyzed all acute care admissions from emergency departments in Ontario, Canada, between 1988 and 1997 (a total of 3,789,917 admissions) and compared in-hospital mortality among patients admitted on a weekend with that among patients admitted on a weekday for 3 prespecified diseases: ruptured abdominal aortic aneurysm, acute epiglottitis, and pulmonary embolism (31). Weekend admissions were associated with significantly higher in-hospital mortality rates than were weekday admissions among patients with the conditions studied. Thus, patients with some serious medical conditions are more likely to die in the hospital if they are admitted on a weekend than if they are admitted on a weekday.

\section{DOG BITES}

Dog bites are a major public health problem. The CDC estimates that 4.5 million people in the USA are bitten each year, and almost half are children under age 12 (32). About 335,000 people are treated at emergency departments annually with dog bite-associated injuries, and about 465,000 are seen in other medical settings. From 1979 through 1994 in the USA, 279 people died from dog attacks. In addition to injury and death, there are economic costs associated with dog bites. The insurance industry estimates it pays more than $\$ 1$ billion annually in homeowners' liability claims resulting from dog bites. Hospital expenses for dog bite-related emergency visits are estimated at $\$ 102$ million annually.

It is difficult to identify which specific breeds are responsible for most attacks on humans. In one study, researchers found that at least $25 \mathrm{dog}$ breeds were involved in 238 human fatalities from 1979 through 1998, with "pit bull-type" and rottweilers accounting for more than half that number. They concluded that while fatal attacks on humans appear to be breed-specific, other breeds may bite and cause fatalities at higher rates because numerator data may be biased. Of 227 deaths for which complete data were available, 55 (24\%) involved unrestrained dogs off their owner's property, 133 (59\%) involved unrestrained dogs on their owner's property, $38(17 \%)$ involved restrained dogs on their owner's property, and $1(<1 \%)$ involved a restrained dog off its owner's property. Only about $10 \%$ of dog bites involve persons unknown to the animal.

Recently, the American Veterinary Medical Association Task Force on Canine Aggression and Human-Canine Interactions published a piece entitled "A Community Approach to Dog Bite Prevention." The document advocates moving away from creating local ordinances targeted at specific dog breeds. Although such an approach is a typical response by a community following an attack, it usually only riles owners of those breeds while 
failing to reduce the number of dog bites. The guidelines are available on the association's Web site at http://www.avma.org/ press/dogbite.pdf.

\section{PROBLEM AND PATHOLOGICAL GAMBLING}

In 1998, US legalized gambling grossed $\$ 50$ billion, more than the motion picture, theme park, and music industries combined (33). An increased prevalence of gambling problems has accompanied the recent rapid expansion of legalized gambling. Since significant adverse consequences often accompany gambling, there is a need to understand, identify, and develop effective treatments for individuals with gambling problems.

Gambling is placing something of value at risk with the hope of gaining something of greater value. In 1998, $86 \%$ of the general adult population in the USA was estimated to have gambled at some point in their lives, up from 68\% in 1975. Traditional forms of gambling include wagering in casinos, lotteries, or horse racing. New gambling forms, such as video poker and Internet gambling, may be more habit forming, given their greater rapidity of action and ability to be used in isolation.

Less than $10 \%$ of adult gamblers develop a gambling problem. Multiple terms have been used to describe problem gambling, including compulsive, addictive, and disordered gambling. The term problem gambling generally refers to gambling that interferes significantly with basic occupational, interpersonal, and financial functioning. Pathological gambling is the most severe form of disordered gambling and includes tolerance, withdrawal, diminished control, and relinquishing of important activities.

Pathological gambling in the USA has past-year and lifetime prevalence rates of $1.1 \%$ and $1.6 \%$, respectively. An additional $2.8 \%$ and $3.8 \%$ of the adult population were estimated to have had problem gambling in the past year or lifetime, respectively. Significantly higher rates were observed in youths and adolescents, with lifetime prevalence rates of $3.9 \%$ for pathological gambling and $9.5 \%$ for problem gambling.

In addition to adolescents, adults in mental health and substance abuse treatment programs have higher rates of problem and pathological gambling, approximately 4- to 10-fold higher than in the general adult population. High rates of mood, psychotic, anxiety, attention-deficit, personality, and substance use disorders have been reported among individuals with problem and pathological gambling. Other high-risk groups include men (whose risk is 2 to 3 times higher than that of women), African Americans (who make up 31\% of individuals with problem or pathological gambling), individuals with a family history of gambling, and individuals of lower socioeconomic status.

Compared with other gamblers and nongamblers, individuals with problem and pathological gambling have higher rates of receipt of past-year unemployment and welfare benefits, bankruptcy, arrest, incarceration, divorce, poor or fair physical health, and mental health treatment. It is estimated that the annual US cost of problem and pathological gambling is about $\$ 5$ billion. About 20\% of pathological gamblers have attempted suicide.

What to do? Although Gamblers Anonymous has helped many people since its inception in 1957, few studies have systematically examined its efficacy. Most gamblers leave the selfhelp program within a year. Although no FDA-approved drug treatments currently exist, encouraging data are emerging from investigations into pharmacological treatments for pathological gambling. These include mainly selective serotonin reuptake inhibitors. The $\mu$-opioid antagonist naltrexone has been effective in the short-term treatment of pathological gambling.

\section{TRAVELING IN AIR VS TRAVELING ON THE GROUND}

According to CNN, flying is 8 times safer than traveling by auto. Each day on US roads the number of auto occupants killed would fill a Boeing 737 airplane!

\section{AIR TRAVEL AND PULMONARY EMBOLISM}

Air travel is a recognized risk factor for pulmonary embolism, but the relation between the distance flown and pulmonary embolism has not been examined. Lapostolle and colleagues from Bobigny, France, and Washington, DC, reviewed all cases of pulmonary embolism requiring medical care among the 135 million passengers who arrived at the Charles de Gaulle Airport from November 1993 to December 2000 (34). Fifty-six confirmed cases of pulmonary embolism were found. The incidence of pulmonary embolism was 1.5 cases per million for those traveling $>3100$ miles and 0.01 case per million for those traveling $<3100$ miles. It was 4.8 cases per million for those traveling $>6200$ miles. Thus, distance traveled is a significant contributing risk factor for pulmonary embolism associated with air travel.

\section{LESS THAN 4000 SUDDEN DEATHS}

The 2 planes that rammed into the Twin Towers in New York City on September 11, 2001, killed instantly just under 4000 persons. The initial estimates were far greater than that. The crashes fortunately occurred before 9 AM, before most workers had arrived for work. In contrast to Dallas, New York City is a "late town," in that most workers usually do not report for work until about 9:00 AM. If the crashes had occurred at 10:00 AM almost certainly many more thousands would have lost their lives. I understand that the numbers of persons who worked in the Twin Towers was approximately 50,000 and that another 50,000 might wander through the towers each day.

\section{BOMBS AND FOOD FROM PLANES IN AFGHANISTAN}

Afghanistan's past 3 years of drought have been the worst in 30 years and have been catastrophic in a country where $85 \%$ of the estimated 21 million population is dependent on agriculture (35). Harvests have failed for a third year in a row, livestock have been decimated, and coping capacities have been severely impaired by an increase in food prices and the collapse of the rural economy. In Kandahar, rivers used as the main source of drinking water and irrigation are totally dry. An outbreak of scurvy appeared in western Afghanistan at the beginning of 2001 .

These desperate conditions have forced millions to flee their homes. By late spring 2001, the number of Afghans taking refuge in neighboring countries had increased to $>4$ million, and possibly as many as 500,000 have been displaced within the country. Conflict, drought, and the food crisis are the main reasons why people flee Afghanistan, where the average lifespan now is only 46 years. There are more landmines in Afghanistan than in any other country on earth except for the demilitarized zone between North and South Korea. 
Although several million pounds of food have been dropped from US planes in Afghanistan since September 11, the United Nations has massively reduced all other aid operations in Afghanistan because of increased security risks. Getting aid into the country is difficult at best and virtually impossible in some locations. Some believe that the US air drops of food are the least effective way of delivering aid because they are untargeted and unmonitored and the supplies rarely reach those who need them the most.

The US Air Force is delivering the food packets to Afghanistan via C-17 cargo jets that fly out of Germany (36). This $\$ 200$ million plane, which was originally designed to carry US Army tanks and troops into battle, is now packed with 17,000 food packets. The plane is loaded with 42 boxes, each containing 410 food packets containing vegetarian meals including rice and beans. Meat is avoided because of religious dietary restrictions; Muslims, for example, eat no pork. The roundtrip flight from Germany is nearly 14 hours. The C-17 has to meet up with a KC135 aerial tanker over the Black Sea to top off its tanks. Then it's on toward Afghanistan.

The 42 boxes are unloaded at 25,000 feet or higher, beyond the reach of known Taliban antiaircraft weapons. The temperature at that height is well below $0^{\circ}$ and oxygen is absent. About 2 hours before the drop, the entire crew dons masks and begins breathing pure oxygen. Starting early helps minimize the risk of nitrogen bubbles forming and causing injury or death. In preparation for deplaning the boxes, they remove the straps that keep the boxes in place during takeoff and refueling. Before opening the doors, the cabin is depressurized because more pressure inside the jet than out would cause everything to be sucked out in a giant rush. When the target area is near, the plane doors are opened. At the critical moment, the jet tips upwards at $7^{\circ}$. The boxes strain at the gate. The crew, tethered to the jet, stand on the sides out of the path of the soon-to-be unleashed freight train. The switch is flipped and in 8 seconds all 42 boxes are discharged from the airplane. The gates are quickly closed and pressure and heat return. For these flights there are at least 6 crew members, including an extra pilot and loadmaster and an Air Force physiologist to watch for altitude sickness. On the return flight they refuel again over the Black Sea. Once the plane lands, new supplies, brought from the USA, are repacked in the C-17 for the next night's flight.

Few countries have dropped bombs and food from airplanes nearly simultaneously in the same war. At least in World War II, we waited until the war was won before feeding the defeated. We probably have no real choice in Afghanistan.

\section{SMALLPOX}

The worry is not anthrax, it's smallpox (37). Smallpox at one time killed 1 of every 3 people it infected and scarred many more. It was so lethal and widespread that the early form of inoculation in the 18th century was considered a boon even though it killed 1 of every 100 recipients.

This infectious disease had the dubious honor of being the first biological weapon. In 1763, beleaguered British troops gave out infected blankets to American Indians! In the 20th century, smallpox killed 300 million people in the world, more than all the wars combined. Then, in the late 1960s, the World Health
Organization launched a campaign to wipe it out. After 13 years and $\$ 100$ million, smallpox officially was defeated, the first infectious disease to be eradicated. We stopped vaccinating. But the Soviets stockpiled military-grade smallpox. Nevertheless, there has not been a case of smallpox since 1978 .

Today, we are like the American Indians of earlier times, unvaccinated and vulnerable. As Jonathan Tucker says in Scourge, getting rid of smallpox was "the greatest achievement of public health in the 20th century." Now, the US government has ordered 300 million doses of smallpox vaccine. We are gearing up to fight a disease that has been eradicated. Biologic warfare has been called "public health in reverse." It dispenses "medicine" to produce disease.

\section{CELEBRATING 100 YEARS OF THE NOBEL PRIZE}

Many prizes recognize intellectual achievement, but none can match the prestige and mystique of the Nobel Prize (38). This prize confers instant celebrity and lifetime certificate as a pioneer on the frontiers of knowledge. The 5 awards established by Alfred Nobel's will—physics, chemistry, physiology or medicine, literature, and peace-were first presented in 1901; a sixth in economic sciences was created in 1969. On the occasion of the 100th anniversary of Nobel's legacy, the Smithsonian's Lemelson Center for the Study of Invention and Innovation has presented an exhibition to celebrate the 700 laureates and their accomplishments.

Nobel directed that the awards be given "to those who, during the preceding year, shall have conferred the greatest benefit on mankind." Except for the peace prize, this instruction has been routinely violated, because most awards are for work performed many years earlier. Nobel's will provided few instructions for selecting prizewinners, other than designating the 4 institutions empowered to make the selections: the Royal Swedish Academy of Sciences, for the physics and chemistry prizes; the Karolinska Institute, for medicine; the Swedish Academy, for literature; and the Norwegian parliament, for peace.

Videotaped interviews with many of the prizewinners, mainly in the sciences, are the focus of the exhibition and provide a glimpse of the motivations and work philosophies of these researchers ( 670 men and 30 women). Their candid comments on the people and the subjects that inspired their efforts convey a consistent theme of hard work, visionary insight, and an enormous pleasure in what they do. They share their thoughts on the value of the award, the state of science in the modern era, political and ethical concerns, and other topics.

The exhibition includes some records of the Nobel committees from the first 50 years of the awards. For example, they show why Einstein was awarded the 1921 prize in physics for studies on the photoelectric effect rather than his revolutionary theory of relativity. The deliberation notes revealed that the members of the Nobel physics committee at that time were biased against theoretical work, especially Einstein's. Unable to ignore this giant of 20th-century science, they settled on the photoelectric effect for his award citation, finding comfort in the fact that it was empirically based and not theoretical.

For Sweden, the prizes are a source of international prestige and are carefully promoted, with phased announcements to stretch out the annual suspense of each award. But, as big-team 
efforts, particularly in physics, biology, and other disciplines, supersede solo genius in science, doubts grow about the validity of picking 1 or 2 winners for great accomplishment. Moreover, the Nobel Prizes ignore some subjects of research, including mathematics, geology, the social sciences, and engineering. There is also the curious business of Nobelists sounding off on issues remote from their professional skills. Nevertheless, the glitter and glory of the Nobel Prize continue undiminished and are likely to remain so for another 100 years or more.

The first American to win a Nobel Prize was not a scientist or a writer. It was Theodore Roosevelt, who was awarded the Nobel Peace Prize in 1906 for negotiating a settlement between the Russians and Japanese at the Treaty of Portmouth, thus ending years of bloody conflict in northeastern Asia.

\section{MANAGED CARE'S DEMISE}

James Robinson had an article in a recent JAMA entitled "The end of managed care" (39). He argued that managed care embodies an effort by employers, the insurance industry, and some elements of the medical profession to establish priorities and decide who gets what from the health care system. After a turbulent decade of trial and error, that experiment can be characterized as an economic success but a political failure. The strategy of giving with one hand while taking away with the other, of offering comprehensive benefits while restricting access, has infuriated everyone involved. The protagonists of managed care now are in full retreat, broadening physician panels, removing restrictions, and reverting to fee-for-service payment. The consumer (patient) is emerging as the locus of priority setting in health care.

\section{"OLD" IS WHEN ...}

Dr. Venkata Ram sent me these: Old is when ... it takes longer to rest than to get tired. You are cautioned to slow down by the doctor instead of by the police. Getting "a little action" means "I don't need to take any fiber today." "Getting lucky" means finding your car in the parking lot. "All-nighter" means not getting up to go to the bathroom. Your sweetie says, "Let's go upstairs and make love," and you answer, "Honey, I can't do both." Your friends compliment you on your new alligator shoes when you are barefoot. You remember when the Dead Sea was only sick. You don't care where your spouse goes, just as long as you don't have to go along.

\section{TEN GREAT FEUDS IN MEDICINE}

Hal Hellman recently produced a book describing 10 great feuds in medicine (40). Here they are: 1) "Harvey versus Primrose, Riolan, and the anatomists (including Galen): circulation of the blood"; 2) "Galvani versus Volta: animal electricity"; 3) "Semmelweis versus the Viennese medical establishment: childbed fever"; 4) "Bernard versus chemists, physicians, and antivivisectionists: experimental medicine"; 5) "Pasteur versus Liebig, Pouchet, and Koch: fermentation, spontaneous generation, and germ theory"; 6) "Golgi versus Ramón y Cajal: the nerve network"; 7) "Freud versus Moll, Breuer, Jung, and many others: psychoanalysis"; 8) "Sabin versus Salk: the polio vaccine"; 9) "Franklin versus Wilkins: the structure of DNA"; and 10) "Gallo versus Montagnier: the AIDS war."

\section{RECOMBINANT DNA}

Donald Fredrickson, who was my immediate boss at the National Institutes of Health for a number of years, has written a book describing the controversy over recombinant DNA from 1974 to 1981, while he was director of the National Institutes of Health (41). The book is largely a detailed description of events during that period. Recombinant DNA technology began in the early 1970s, and it completely changed the world of biology and medicine. In essence, this technology allowed the combining of segments of genetic material from essentially any organism, using simple enzymatic reactions in test tubes, and the propagation of the resulting recombinant DNA in living organisms such as Escherichia coli and mammalian cells. Recombinant DNA technology is used in virtually every area of biology, and it is hard to imagine the explosion of biologic information during the past 30 years without it. Among the numerous benefits of recombinant DNA technology are the large-scale production of proteins of therapeutic value, the development of diagnostic tests for HIV, the sequencing of the human genome, the use of DNA testing in criminal trials, the creation of genetically modified plants, and current efforts in gene therapy. Recombinant DNA technology also initiated the change in biology from an academic discipline to a major industry. Fredrickson's memoir is a valuable historical document.

\section{LIFE EXPECTANCY FOR WOMEN AND MEN AT SELECTED AGES}

Median life expectancies of persons in the USA are summarized in Figure 2 by age and sex (42). Although it is useful to know median life expectancies, it may be more helpful to have a general idea of the distribution of life expectancies at various ages. For example, when making screening decisions about a 75-year-

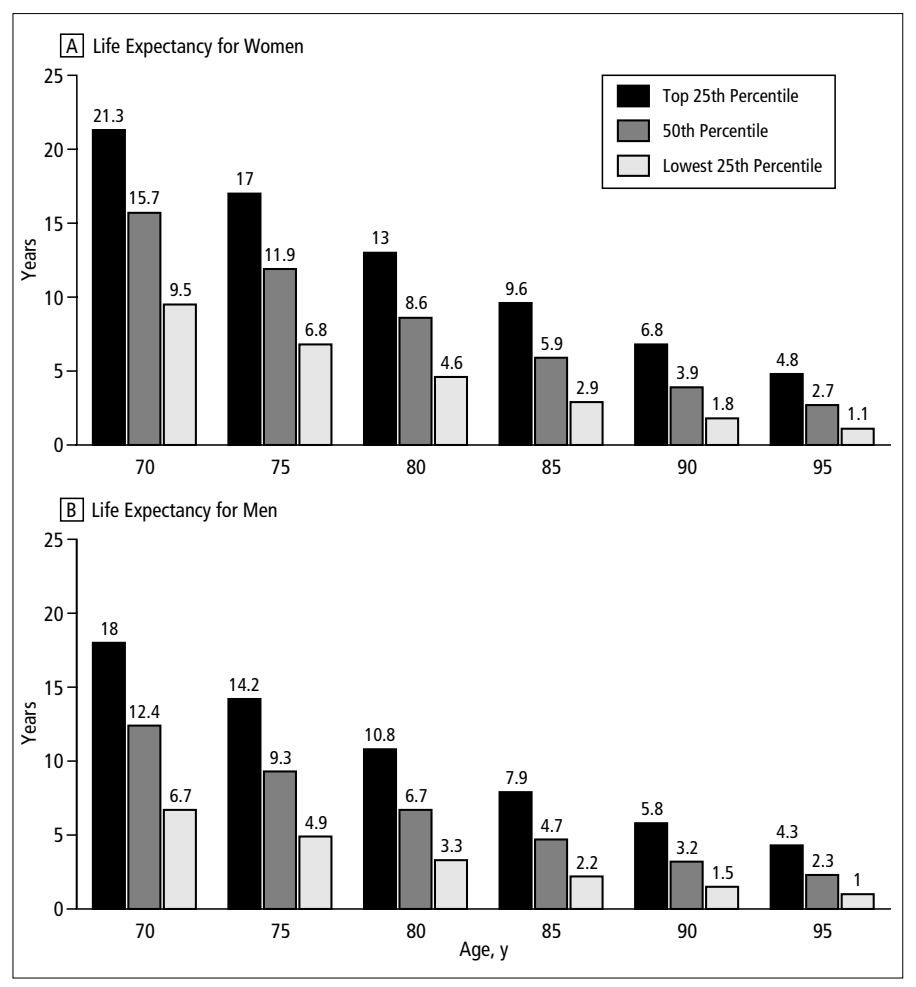

Figure 2. Upper, middle, and lower quartiles of life expectancy for women and men at selected ages. (JAMA 2001;285:2751. Copyrighted 2001. American Medical Association.) 
old woman, it is useful to know that approximately $25 \%$ of 75 year-old women will live $\geq 17$ years, $50 \%$ will live at least 12 years, and $25 \%,<7$ years. Thus, there is substantial variability in life expectancy at each age and in each sex. Although it is impossible to predict the exact life expectancy of an individual patient, it is possible to make reasonable estimates of whether a patient is likely to live substantially longer or shorter that an average person in his or her age group.

\section{ASTRE'S SEMEN}

Astre is a bull who weighs 2600 pounds and is the father of 460,000 offspring (43). By the time this bull retires, he probably will have sired close to a million calves. His owner, Douglas Blair, will eventually reap $\$ 18$ million from selling Astre's semen. A top bull can bring in as much as $\$ 110$ for a strawful of semen. (The average bull gets $\$ 10$ for a "straw," which is about the size of a ballpoint pen refill. It usually takes a little less than 2 strawfuls to fertilize 1 cow.) Only 1 in every 1000 bulls becomes a super elite sire like Astre. In 2001, Douglas Blair will buy 250 baby bulls, paying around $\$ 4500$ for each. When the bulls are a year old, their semen will be collected and artificially inseminated into hundreds of dairy cows. Three years later, as the bulls' offspring begin to milk, the milk will be evaluated. For a bull to be deemed tops, its offspring will have to consistently produce lots of milk. While an average cow produces 18,000 pounds of milk a year, Astre's offspring average 21,000 pounds. And quantity isn't all that matters: the milk must be high in protein and modest in butterfat.

Blair's first investment was to buy a $\$ 570$ young beef bull from Switzerland. In just 6 years, Blair's Swiss bull returned $\$ 1$ million. After a few years, however, Blair recognized that it made more sense to sell the sperm of high-quality dairy bulls than of beef bulls. A superior beef calf may bring a farmer only an additional $\$ 25$ when sold, whereas a super dairy cow might bring in $\$ 180$ more a year in extra milk production. So Blair changed his strategy. Instead of buying 2 or 3 bulls a year hoping one would hit the jackpot, he opted to improve his odds by stocking his barn with many more bulls.

Blair then went into the fertilized embryo business. While artificially inseminating semen provides superior genetics only from the bull, taking embryos from a top-producing milk cow and fertilizing them with the sperm from a top stud gives farmers the best of both sexes. Since any cow in the world can host the fertilized egg of a super stud breed to a super cow, that means that an elite cow can produce not just 1 calf a year, but as many as 20 a year.

Human medicine is a bit more appealing to me.

\section{SAMUEL GOLDWYN}

When young Schmuel Gelbfisz decided to leave Warsaw, Poland, at age 16, he just started walking (44). He ended up in England, where he stayed for a couple of years, and then in 1898 he sailed to North America and walked from Nova Scotia to New York. Samuel Goldfish, the name he adopted in England, started in America sweeping floors for a glove company and was soon a top salesman. Early on he fell in love with movies and went into the business. With another partner he eventually formed the Goldwyn Company and sneakily changed his last name to
Goldwyn. That name soon developed a reputation for excellence, because Goldwyn always professed to value quality over numbers. He produced many of the best pictures from about 1910 to about 1960. He died in 1974 at the home he shared with his wife of 49 years. He was also known for his malapropish comments, which became known as Goldwynisms. Some included "include me out" and "anyone who goes to a psychiatrist should have his head examined."
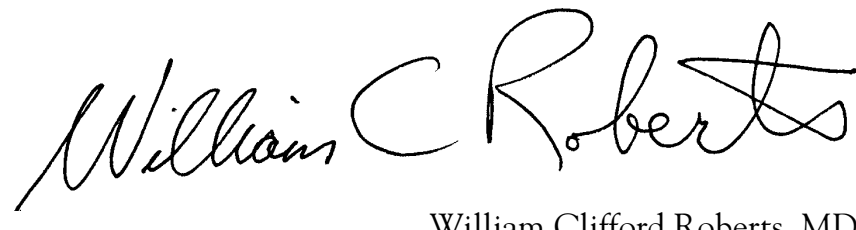

William Clifford Roberts, MD

1. White DG, Zhao S, Sudler R, Ayers S, Friedman S, Chen S, McDermott PF, McDermott S, Wagner DD, Meng J. The isolation of antibiotic-resistant salmonella from retail ground meats. N Engl J Med 2001;345:11471154.

2. McDonald LC, Rossiter S, Mackinson C, Wang YY, Johnson S, Sullivan M, Sokolow R, DeBess E, Gilbert L, Benson JA, Hill B, Angulo FJ. Quinupristindalfopristin-resistant Enterococcus faecium on chicken and in human stool specimens. N Engl J Med 2001;345:1155-1160.

3. Sørensen TL, Blom M, Monnet DL, Frimodt-Moller N, Poulsen RL, Espersen F. Transient intestinal carriage after ingestion of antibiotic-resistant Enterococcus faecium from chicken and pork. N Engl J Med 2001;345:1161-1166.

4. Gorbach SL. Antimicrobial use in animal feed-time to stop. N Engl J Med 2001;345:1202-1203.

5. Hyman DJ, Pavlik VN. Characteristics of patients with uncontrolled hypertension in the United States. N Engl J Med 2001;345:479-486.

6. Vasan RS, Larson MG, Leip EP, Evans JC, O'Donnell CJ, Kannel WB, Levy D. Impact of high-normal blood pressure on the risk of cardiovascular disease. N Engl J Med 2001;345:1291-1297.

7. Scuteri A, Bos AJ, Brant LJ, Talbot L, Lakatta EG, Fleg JL. Hormone replacement therapy and longitudinal changes in blood pressure in postmenopausal women. Ann Intern Med 2001;135:229-238.

8. Schaumberg DA, Buring JE, Sullivan DA, Dana MR. Hormone replacement therapy and dry eye syndrome. JAMA 2001;286:2114-2119.

9. State-specific trends in high blood cholesterol awareness among persons screened-United States, 1991-1999. MMWR 2001;50:754-758.

10. Roberts WC. Living with a congenitally bicuspid aortic valve. Am J Cardiol 1989;64:1408-1409.

11. Novaro GM, Tiong IY, Pearce GL, Lauer MS, Sprecher DL, Griffin BP. Effect of hydroxymethylglutaryl coenzyme A reductase inhibitors on the progression of calcific aortic stenosis. Circulation 2001;104:2205-2209.

12. Exner DV, Dries DL, Domanski MJ, Cohn JN. Lesser response to angiotensin-converting-enzyme inhibitor therapy in black as compared with white patients with left ventricular dysfunction. N Engl J Med 2001;344: 1351-1357.

13. Yancy CW, Fowler MB, Colucci WS, Gilbert EM, Bristow MR, Cohn JN, Lukas MA, Young ST, Packer M. Race and the response to adrenergic blockade with carvedilol in patients with chronic heart failure. N Engl J Med 2001;344:1358-1365.

14. Rose EA, Gelijns AC, Moskowitz AJ, Heitjan DF, Stevenson LW, Dembitsky W, Long JW, Ascheim DD, Tierney AR, Levitan RG, Watson JT, Meier P for the Randomized Evaluation of Mechanical Assistance for the Treatment of Congestive Heart Failure (REMATCH). Long-term use of a left ventricular assist device for end-stage heart failure. N Engl J Med 2001;345:1435-1443.

15. Yusuf S, Gerstein H, Hoogwerf B, Pogue J, Bosch J, Wolffenbuttel BH, Zinman B. Ramipril and the development of diabetes. JAMA 2001;286:18821885.

16. Lewis EJ, Hunsicker LG, Clarke WR, Berl T, Pohl MA, Lewis JB, Ritz E, Atkins RC, Rohde R, Raz I. Renoprotective effect of the angiotensinreceptor antagonist irbesartan in patients with nephropathy due to type 2 diabetes. N Engl J Med 2001;345:851-860.

17. Brenner BM, Cooper ME, de Zeeuw D, Keane WF, Mitch WE, Parving HH, 
Remuzzi G, Snapinn SM, Zhang Z, Shahinfar S. Effects of losartan on renal and cardiovascular outcomes in patients with type 2 diabetes and nephropathy. N Engl J Med 2001;345:861-869.

18. Horner K. Bigger isn't better, tubby Texans told. Dallas Morning News, October 31, 2001.

19. Van den Berghe G, Wouters P, Weekers F, Verwaest C, Bruyninckx F, Schetz M, Vlasselaers D, Ferdinande P, Lauwers P, Bouillon R. Intensive insulin therapy in critically ill patients. N Engl J Med 2001;345:1359-1367.

20. Ades PA. Cardiac rehabilitation and secondary prevention of coronary heart disease. N Engl J Med 2001;345:892-902.

21. Herndon DN, Hart DW, Wolf SE, Chinkes DL, Wolfe RR. Reversal of catabolism by beta-blockade after severe burns. N Engl J Med 2001;345:12231229.

22. Lydon-Rochelle M, Holt VL, Easterling TR, Martin DP. Risk of uterine rupture during labor among women with a prior cesarean delivery. $N$ Engl J Med 2001;345:3-8.

23. Greene MF. Vaginal delivery after cesarean section—is the risk acceptable? N Engl J Med 2001;345:54-55.

24. Löffler R. Wiener Med Woch 1901;10:472 (reprinted in JAMA 2001; 285:2173).

25. Weiss HB, Songer TJ, Fabio A. Fetal deaths related to maternal injury. JAMA 2001;286:1863-1868.

26. Giebink GS. The prevention of pneumococcal disease in children. N Engl J Med 2001;345:1177-1183.

27. Ramsay S. "Shocking" AIDS data released in South Africa. Lancet 2001; 358:1345

28. Vastag B. Suicide prevention plan calls for physicians' help. JAMA 2001; 285:2701-2703.

29. in 'T Veld BA, Ruitenberg A, Hofman A, Launer LJ, van Duijn CM, Stijnen T, Breteler MMB, Stricker BHC. Nonsteroidal antiinflammatory drugs and the risk of Alzheimer's disease. N Engl J Med 2001;345:1515-1521.
30. Singletary KW, Gapstur SM. Alcohol and breast cancer: review of epidemiologic and experimental evidence and potential mechanisms. JAMA 2001;286:2143-2151.

31. Bell CM, Redelmeier DA. Mortality among patients admitted to hospitals on weekends as compared with weekdays. N Engl J Med 2001;345:663-668.

32. Mitka M. Control "social carnivores" to prevent bites. JAMA 2001;286:153_ 154.

33. Potenza MN, Kosten TR, Rounsaville BJ. Pathological gambling. JAMA 2001;286:141-144.

34. Lapostolle F, Surget V, Borron SW, Desmaizieres M, Sordelet D, Lapandry C, Cupa M, Adnet F. Severe pulmonary embolism associated with air travel. N Engl J Med 2001;345:779-783.

35. Ford N, Davis A. Chaos in Afghanistan: famine, aid, and bombs. Lancet 2001;358:1543-1544.

36. Komarow S. Air Force delivers aid with attitude. USA Today, November 9, 2001.

37. Goodman E. Smallpox still the nightmare of bioterrorism. Dallas Morning News, November 7, 2001

38. Reif W. 100 years of Alfred Nobel's legacy. Lancet 2001;358:1280.

39. Robinson JC. The end of managed care. JAMA 2001;285:2622-2628.

40. Hellman H. Feuds. Great Feuds in Medicine: Ten of the Liveliest Disputes Ever. New York: John Wiley \& Sons, 2001.

41. Fredrickson DS. The Recombinant DNA Controversy: A Memoir-Science, Politics, and the Public Interest; 1974-1981. Washington, DC: ASM Press, 2001.

42. Walter LC, Covinsky KE. Cancer screening in elderly patients: a framework for individualized decision making. JAMA 2001;285:2750-2756.

43. Mao P. The other bull market. Forbes, September 9, 2001.

44. Gates A. From Warsaw to Hollywood, a film mogul's odyssey. New York Times, October 6, 2001. 